\title{
A CASE OF A RECIPROCAL TRANSLOCATION BETWEEN THE Y AND NO. 1 CHROMOSOMES
}

\author{
Kouji Narahara, Hiroshi Yabudchi, Shunsuke Kimura and Hiroshi Kimoto \\ Department of Pediatrics, Okayama University Medical School, Okayama, Japan
}

\begin{abstract}
Summary A reciprocal translocation between the $\mathrm{Y}$ and No. 1 chromosomes was found in a male infant with psychomotor retardation and infantile spasms. The karyotype was designated as 46,X,t(1; Y) (q21; q11) on the basis of G- and Q-banding analyses. Previously reported cases with $\mathrm{Y} /$ autosomal translocations are reviewed.
\end{abstract}

\section{INTRODUCTION}

Since banding techniques were introduced, many cases of structural abnormalities of the $\mathrm{Y}$ chromosome have been described; isochromosomes of the long arm (Book et al., 1973; Magnelli et al., 1974) and short arm (Siebers et al., 1973), pericentric inversions (Grace et al., 1972; Zeuthen and Nielsen, 1973), deletion of the long arm (Meisner and Inborn, 1972) and dicentric Y chromosomes (Cohen et al., 1973). However, relatively few cases of translocation between autosomes and Y chromosomes have been reported. This report describes a case of a de novo Y/1 translocation.

\section{CASE REPORT}

The proband was a 4-month-old male infant, born at term to a 21 -year-old primigravid mother, whose pregnancy, labor and delivery were uneventful. The father was 26 years old. The birth weight was $3,050 \mathrm{~g}$. Family history was not contributory. The infant exhibited neonatal hyperbilirubinemia which was treated by phototherapy. During the newborn period he had feeding difficulties and vomited frequently after sucking. At the age of 4 months, he was referred to us because of poor weight gain, psychomotor retardation and massive myoclonic spasms. Physical examination showed a small malnourished infant but no obvious malformations. His height was $60.0 \mathrm{~cm}$ (10th percentile), weight 4,490 g (less than third percentile) and head circumference $39.5 \mathrm{~cm}$ (10th percentile). The external genitals were those of a normal male. His psychomotor development was grossly retarded with no head control or visual following. Neurologic examination indicated muscular hypotonia, hyperreflexia and dysphagia. Dermatoglyphic study showed eight

Received January 11, 1978 
loops, one whorl and one arch on the fingertips. Simian creases were present on the both hands.

The laboratory data (complete blood count, urinalysis, serum electrolytes, serum cholesterol, blood urea nitrogen, serum transaminase and alkaline phosphatase, serum thyroid and growth hormone values) were all within normal ranges. Cerebrospinal fluid protein and cell count were normal. Urinary screening was negative for metabolic disorders. X-ray examinations of the chest, skull and hip joints and an intravenous pyelogram were normal. Electroencephalography showed a modified pattern of hypsarrhythmia and computed tomography of the head indicated diffuse cortical atrophy of the brain with mild dilatation of both lateral ventricles. Since the age of 3 months, seizures of infantile spasms had occurred several times a day. These seizures had been refractory to usual medications and ACTH therapy of 4 weeks duration was initiated at the age of 6 months. He was discharged at the age of 8 months, when seizures had been controlled and electroencephalographic improvements had been obtained. However, there had been little somatic and psychomotor development during the admission.

\section{CYTOGENETIC FINDINGS}

Peripheral blood was cultured in a usual manner. Chromosome preparations

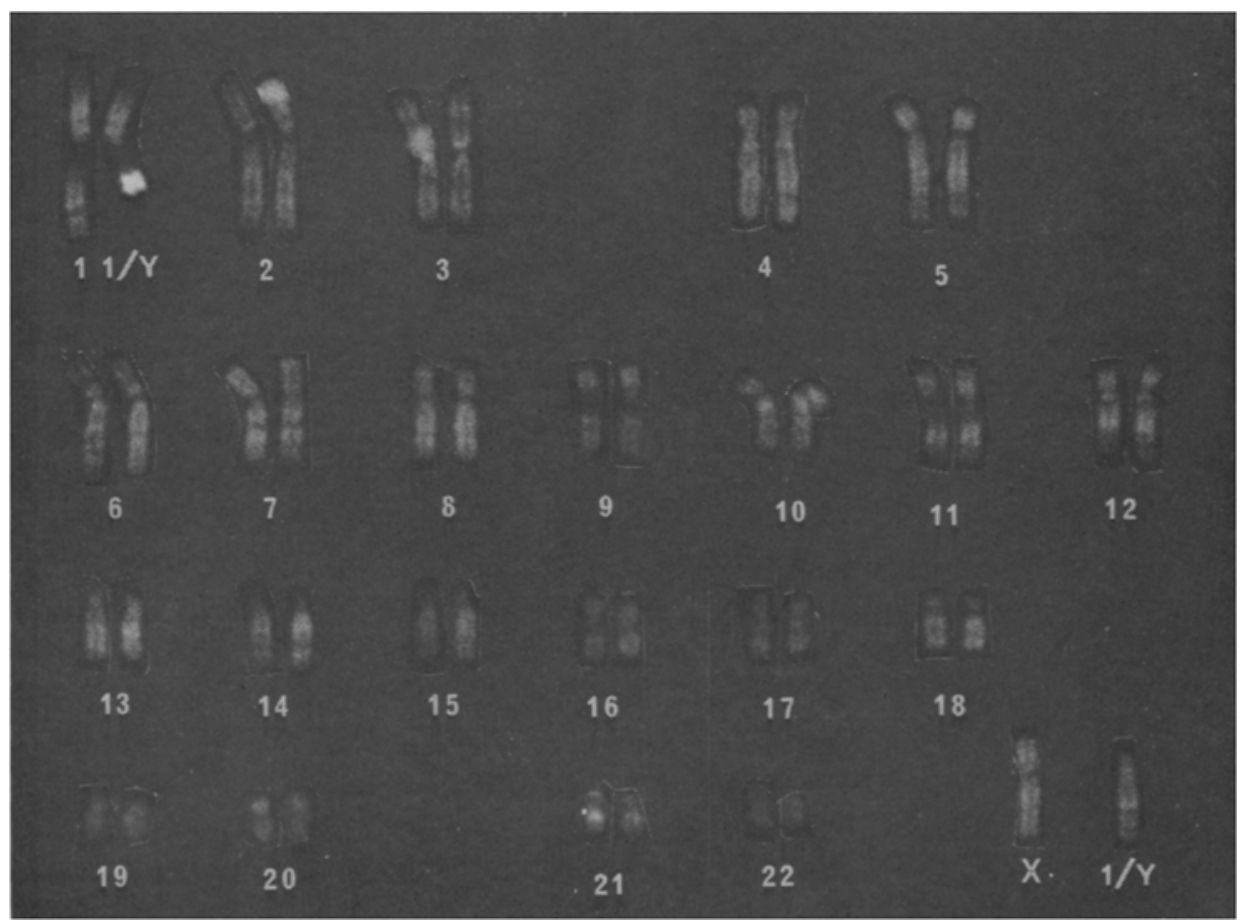

Fig. 1. Q-banding karyotype of the proband. Note a reciprocal transiocation between the No. 1 and the $\mathrm{Y}$ chromosomes. 


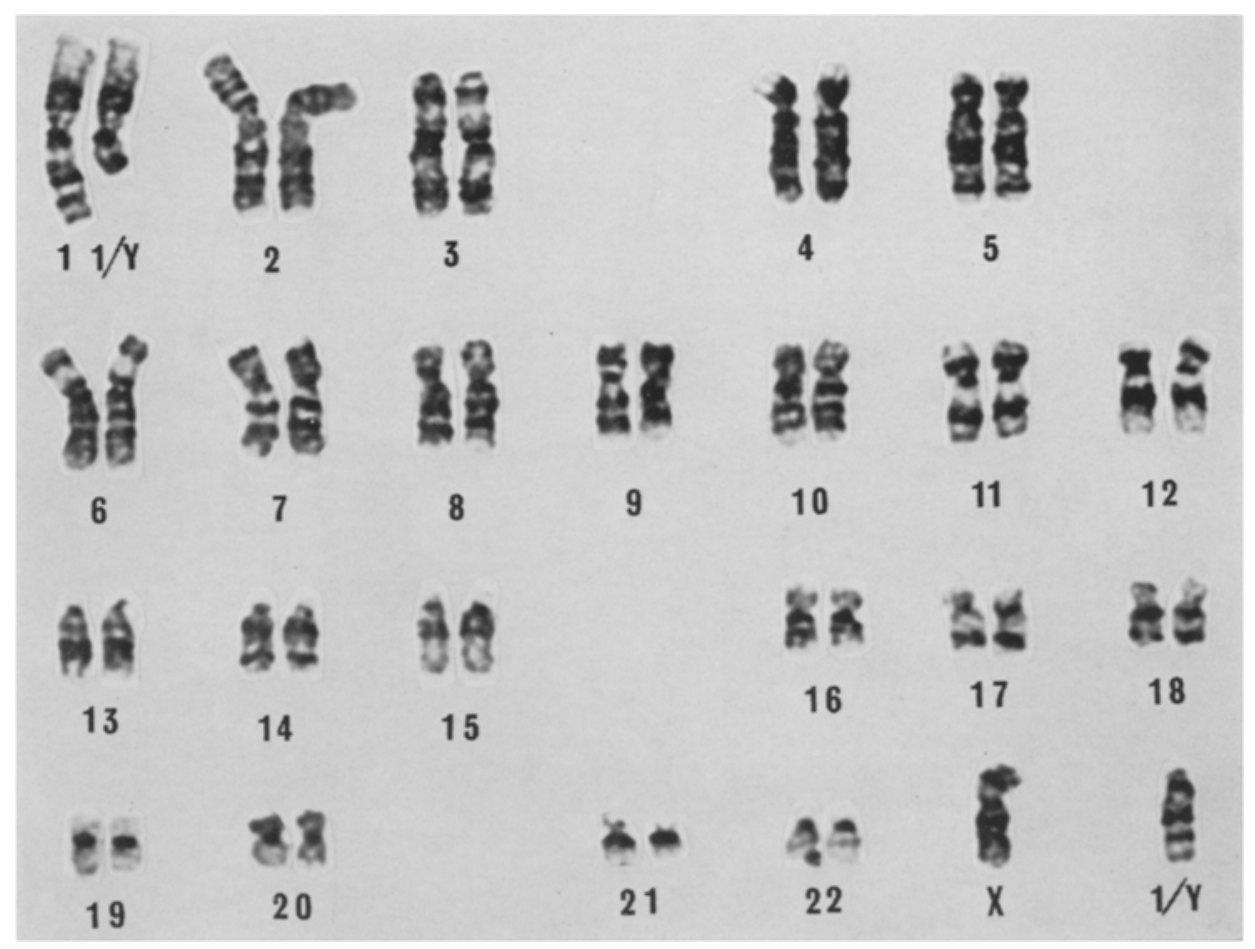

Fig. 2. G-banding karyotype of the proband.

were submitted to conventional Giemsa staining, G-banding (Seabright, 1971, with minor modifications) and Q-banding (Caspersson et al., 1970). Conventional staining showed that in all 30 metaphases examined a No. 1 chromosome and a Y chromosome had been replaced by two unusual chromosomes; one was an acrocentric chromosome somewhat larger than those of D group, the other was a submetacentric one approximating to No. 6 chromosome in form and size. QMfluorescence study showed a reciprocal translocation between the distal four-fifths of the long arm of the No. 1 chromosome and the distal half of the long arm of the Y chromosome (Fig. 1). All the other chromosomes showed normal G-banding patterns (Fig. 2). G-banding analysis made more precise identification of the break-points possible. The breaks appeared to occur at the q21 band of the No. 1 chromosome and at the q11 band of the Y chromosome. The latter break-point was considered to be just above the junction of the fluorescent and nonfluorescent part of long arm of the Y chromosome. According to the Paris Conference (1971) nomenclature, the karyotype was designated as $46, \mathrm{X}, \mathrm{t}(1 ; \mathrm{Y})(\mathrm{q} 21 ; \mathrm{q} 11)$. Karyotypes of both parents were normal. 


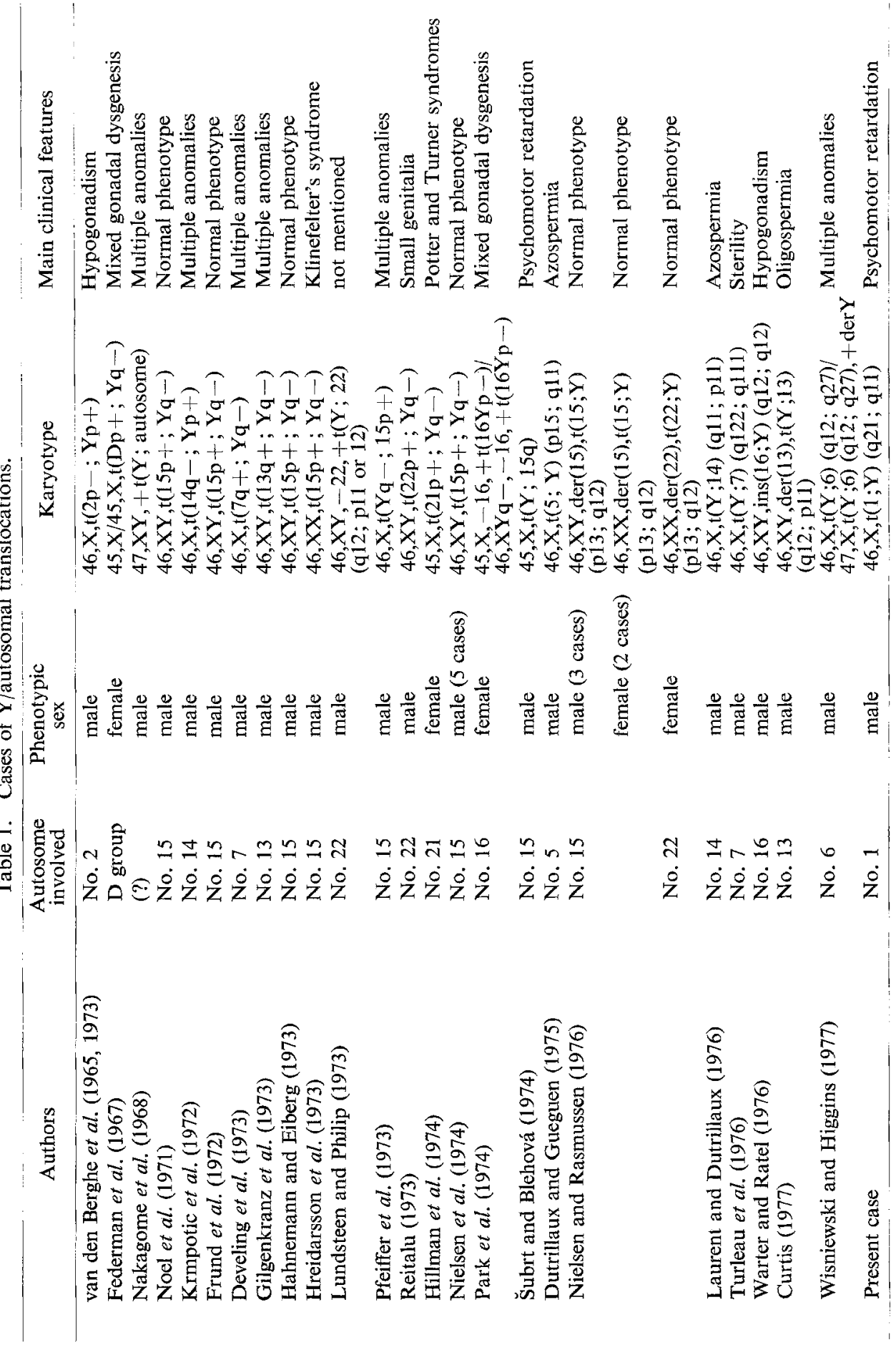




\section{DISCUSSION}

Before banding techniques were introduced into chromosome studies, several cases of Y/autosomal translocations (van den Berghe et al., 1965; Federman et al., 1967; Nakagome et al., 1968) had already been reported. Since identification of involved autosomes in $\mathrm{Y}$ /autosomal translocations became possible by the use of banding methods, 32 cases of confirmed Y/autosomal translocations including our case have been reported (Table 1); Y/15 (Noel et al., 1971; Frund et al., 1972; Pfeiffer et al., 1973; Hreidarsson et al., 1973; Hahnemann and Eiberg, 1973; Nielsen et al., 1974; Šubrt and Blehová, 1974; Nielsen and Rasmussen, 1976), Y/22 (Reitalu, 1973; Lundsteen and Philip, 1973; Nielsen and Rasmussen, 1976), Y/2 (van den Berghe et al., 1973), Y/5 (Dutrillaux and Gueguen, 1975), Y/6 (Wisniewski and Higgins, 1977), Y/7 (Develing et al., 1973; Turleau et al., 1976), Y/13 (Gilgenkranz et al., 1973; Curtis, 1977), Y/14 (Krmpotic et al., 1972; Laurent and Dutrillaux, 1976), Y/16 (Park et al., 1974; Warter and Ratel, 1976), Y/21 (Hillman et al., 1974). To our knowledge, our case is the first report of a $\mathrm{Y} / 1$ translocation. As summarized in Table 1, acrocentric autosomes are frequently involved in $Y$ /autosomal translocations. $\mathrm{Y} / 15$ translocation is the most common type and 16 cases have been reported. All but three cases of Y/15 translocations (Hreidarsson et al., 1973; Pfeiffer et al., 1973; S̆ubrt and Blehová, 1974) showed a normal phenotype. In all of those with a normal phenotype, heterochromatic segment of the long arm of the $\mathrm{Y}$ chromosome that is genetically inert was additionally translocated to the short arms of the No. 15 chromosome. This chromosomal duplication-deficiency did not seem to yield any phenotypic effect. In contrast, cases other than those of $\mathrm{Y} / 15$ translocations showed some phenotypic abnormalities even where the chromosome changes were apparently balanced. Our case, whose chromosome constitution was an apparently balanced translocation, showed severe psychomotor retardation, infantile spasms and hypotonia. The appearance of these phenotypic abnormalities and the balanced translocation may be coincidental, or the two may be causally related. If causal relationship exists between the two, the abnormal phenotype may be caused by a small microscopically undetectable loss of the involved chromosomes occuring during the translocation process or by a "position effect" on vital genes produced by the translocation.

Finally, chromosome analyses in cases of structural aberrations and translocations of the $\mathrm{Y}$ chromosomes have made great contributions to the study of the location of the testis differentiating gene on the $\mathrm{Y}$ chromosome. Since individuals with isochromosomes of the long arms of the $Y$ chromosome have a Turner syndrome, the location of the testis differentiating gene has been thought to be on the short arm of the Y chromosome. Krmpotic et al. (1972) reported a baby with the karyotype $46, \mathrm{X}, \mathrm{t}(\mathrm{Yp}+; 14 \mathrm{q}-)$ who showed a normal male phenotype and suggested that this gene may be located on the centromeric portion of the short arm of the $\mathrm{Y}$ chromosome, while Sieber et al. (1973) proposed the proximal part of the long arm of the 
$\mathrm{Y}$ chromosome as the site of the gene from the observation that their proband with $45, \mathrm{X} / 46, \mathrm{X}, \mathrm{i}(\mathrm{Yp})$ karyotype showed a Turner syndrome. The translocated $\mathrm{Y}$ chromosome of our case contained both the whole short arm and the proximal half of the long arm of the $\mathrm{Y}$ chromosome. Therefore, it is reasonable that our case showed a normal testicular differentiation.

\section{REFERENCES}

van den Berghe, H., Steeno, O., Verresen, H., and de Moor, P. 1965. Hypogonadism associated with chromosomal break in autosome No. 2 and translocation presumably on the $\mathrm{Y}$ chromosome. J. Clin. Endocrinol. 25: 1246-1250.

van den Berghe, H., Fryns, J.P., and David, G. 1973. An autosome-Y translocation restudied. Hum. Genet. 20: 375-376.

Book, J.A., Eilon, B., Halbrecht, I., Komlos, L., and Shabtay, F. 1973. Isochromosome Y (46,X, $\mathrm{i}(\mathrm{Yq})$ ) and female phenotype. Clin. Genet. 4: 410-414.

Caspersson, T., Zech, L., Johansson, C., and Modest, E.J. 1970. Identification of human chromosomes by DNA-binding fluorescent agents. Chromosoma 30: 215-227.

Cohen, M.M., MacGillivrary, M.H., Capraro, V.J., and Aceto, T.A. 1973. Human dicentric Y chromosomes; case report and review of the literature. J. Med. Genet. 10: 74-79.

Curtis, D.J. 1977. Meiotic chromosomes in an infertile male with an unbalanced Y/13 translocation. Hum. Genet. 37: 249-254.

Develing, A.J., Conte, F.A., and Epstein, C.J. 1973. A Y-autosome translocation 46,X,t(Yq-; $7 \mathrm{q}+$ ) associated with multiple congenital anomalies. J. Pediatr. 82: 495-498.

Dutrillaux, B. and Gueguen, J. 1975. Etude méiotique et mitotique dans un cas de translocation $\mathrm{t}(5 ; \mathrm{Y})$. Hum. Genet. 27: 241-245.

Federman, D.D., Davidoff, F.M., and Quellette, E. 1967. Presumptive Y/D translocation in mixed gonadal dysgenesis. J. Med. Genet. 4: 36-40.

Frund, S., Koske-Westphal, T., Fuchs-Mecke, S., and Passarge, E. 1972. Quinacrine mustard fluorescence of a second $\mathrm{Y}$ chromosome in a $\mathrm{Y}$-autosomal translocation. Hum. Genet. 14: 133-136.

Gilgenkranz, S., Pierson, M., and Mauuary, G. 1973. Chromosome 13q+ par translocation probable d'un Y surnumeraire. Ann. Génét. 16: 167-172.

Grace, H.J., Alley, F.E., and Pruk, M.A. 1972. 46,X,inv $(\mathrm{Yp}+\mathrm{q}-)$ in four generations of an Indian family, J. Med. Genet. 9: 293-297.

Hahnemann, N. and Eiberg, H. 1973. Antenatal genetic diagnosis in a kindred with a $15 \mathrm{p}+$ chromosome. Clin. Genet. 4: 464-473.

Hillman, L.S., Sekhon, G.S., Kaufman, R.L., and Ho, C.-K. 1974. Y/21 translocation with gonadal and renal dysgenesis and cardiac rupture. Am. J. Dis. Child. 128: 560-564.

Hreidarsson, A.B., Nielsen, J., and Berggreen, S. 1973. Presumptive Y/15 translocation and mental retardation in a family with a case of Klinefelter's syndrome. J. Ment. Defic. Res. 17: 163-170.

Krmpotic, E., Szego, K., Modestas, R., and Molabola, G.B. 1972. Localization of male determining factor on short arm of $Y$ chromosome: case report of a baby with $46, X, t(Y p+; 14 q-)$. Clin. Genet. 3: 381-387.

Laurent, C. and Dutrillaux, B. 1976. Translocation t(Y;14) chez un homme azoospermique. Ann. Génét. 19: 207-209.

Lundsteen, C. and Philip, J. 1973. Y/22 translocation in a YY male. Cytogenet. Cell Genet. 12: 53-59.

Magnelli, N.C., Vianna-Morgante, A.M., Frota-Pessoa, O., and Taboada-Lopez, M.G. 1974. Turner's syndrome and 46,X,i(Yq) karyotype. J. Med. Genet. 11: 403-406. 
Meisner, L.F., and Inhorn, S.L. 1972. Normal male development with Y chromosome long arm deletion (Yq-). J. Med. Genet. 19: 373-377.

Nakagome, Y., Smith, H.D., and Soukup, S.W. 1968. A presumptive Y-autosome translocation in a boy with congenital malformations. Am. J. Dis. Child. 116: 205-210.

Nielsen, J., Friedrich, U., Hreidarsson, A.B., Noel, B., Quack, B., and Mottet, J. 1974. Brilliantly fluorescing enlarged short arms D or G. Lancet 1: 1049-1050.

Nielsen, J. and Rasmussen, K. 1976. Y/autosomal translocations. Clin. Genet. 9: 609-617.

Noel, B., Emerit, I., Luciani, J.M., and Quack, B. 1971. A familial Y/autosome translocation in man. Clin. Genet. 2: 1-6.

Park, I.J., Heller, R.H., Jones, H.W., and Woodruff, J.D. 1974. Apparent pseudopuberty in phenotypic female with a gonadal tumor and an autosome-Y chromosome translocation. Am. $J$. Obstet. Gynecol. 119: 661-668.

Pfeiffer, R.A., Bier, L., Majewski, F., and Rager, K. 1973. De novo translocation $\mathrm{t}(\mathrm{Yq}-; 15 \mathrm{p}+)$ in a malformed boy. Hum. Genet. 19: 349-352.

Reitalu, J. 1973. A familial Y-22 translocation in man. Hereditas 74: 155-160.

Seabright, M.A. 1971. A rapid banding technique for human chromosomes. Lancet. 2: 971-972.

Siebers, J.W., Vogel, W., Hepp, H., Bolze, H., and Dittrich, A. 1973. Structural aberrations of the $\mathrm{Y}$ chromosome and the corresponding phenotype. Report of a case with the karyotype 45,X/ 46,X,i(Yp). Hum. Genet. 19: 57-66.

Subrt, I. and Blehová, B. 1974. Robertsonian translocation between the chromosome Y and 15. Hum. Genet. 23: 305-309.

Turleau, C., Croquette, M.-F., Fourlinnie, J.-C., Desmons, F., and de Grouchy, J. 1976. Translocation 46,X,t(Y;7) (q122;q111) dans un cas de stérilité masculine. Ann. Génét. 19: 210-212.

Warter, S. and Ratel, J.L. 1976. Translocation de l'Y sur un autosome et hypogonadisme. Hum. Genet. 33, 335-336.

Wisniewski, L. and Higgins, J.V. 1977. Mosaicism presumably related to a Y/6 translocation in a boy with multiple congenital $a b_{\text {s }}$ Genet. 14: 378-381.

Zeuthen, E. and Nieisen, J. 1973. Fur.us... . .......... in the general population. Hum. Genet. 19: $265-270$. 